(C) 2008 The Japan Society of Applied Physics

\title{
Visible Electroluminescence from Spherical-Shaped Silicon Nanocrystals
}

\author{
Hea Jeong Cheong ${ }^{1}$, Atsushi TANAKA ${ }^{1,4}$, Daihei HipPo ${ }^{1,4}$, Kouichi UsAmi ${ }^{1}$, \\ Yoshishige TsuchiYA ${ }^{1,4}$, Hiroshi MizuTA ${ }^{2,3,4}$, and Shunri OdA ${ }^{1,4}$ \\ ${ }^{1}$ Quantum Nanoelectronics Research Center, Tokyo Institute of Technology, 2-12-1 O-okayama, Meguro-ku, Tokyo 152-8552, Japan \\ ${ }^{2}$ School of Electronics and Computer Science, University of Southampton, Highfield, Southampton SO17 1BJ, U.K. \\ ${ }^{3}$ Department of Physical Electronics, Tokyo Institute of Technology, 2-12-1 O-okayama, Meguro-ku, Tokyo 152-8552, Japan \\ ${ }^{4}$ SORST JST (Japan Science and Technology), 4-1-8 Honcho, Kawaguchi, Saitama 332-0012, Japan
}

(Received February 23, 2008; accepted July 23, 2008; published online October 17, 2008)

We fabricated light emitting diodes (LEDs) using spherically shaped nanocrystalline silicon (nc-Si), which was formed through very high frequency (VHF; $144 \mathrm{MHz}$ ) plasma decomposition of $\mathrm{SiH}_{4}$. In addition, we successfully reduced the roughness of the surface and part of the voids separating the dots by finding the adequate annealing conditions. Red electroluminescence was also observed at $12 \mathrm{~V}$ with the naked eye at room temperature under forward bias condition. It is suggested that the origin of the electroluminescence (EL) from $\mathrm{Si}$ nanocrystals is due to recombination centers in $\mathrm{Si}$ nanocrystals by the comparison of EL and photoluminescence spectra. [DOI: 10.1143/JJAP.47.8137]

KEYWORDS: VHF plasma CVD, spherical shaped silicon nanocrystals, phosphorous diffusion, photoluminescence, electroluminescence

\section{Introduction}

Since maintaining the scaling-down trend using the topdown method based on lithography is getting increasingly difficult both technologically and economically in silicon nanoelectronics, bottom-up technologies for fabricating silicon nanostructures have attracted a lot of interest. We have developed a novel method of fabricating spherical shaped nanocrystalline silicon (nc-Si) dots by using very high frequency (VHF) pulsed-gas plasma processes, and have obtained monodispersed particles of nc-Si with the size of $8 \pm 1 \mathrm{~nm} .{ }^{1-3)}$ Compared to the Si dots fabricated at high temperature, ${ }^{4)}$ those made through our method are highly crystallized in nature even though the dots were fabricated at room temperature. Moreover, these fabricated dots can be oxidized at a temperature lower than $800^{\circ} \mathrm{C}$ to further reduce their size. ${ }^{5)}$ In order to apply these bottom-up-made spherical nc-Si dots to silicon nanodevices, we have attempted to integrate them into the top-down-fabricated nanoelectrodes and have already reported on single electron devices, ${ }^{6}{ }^{6}$ single electron memory ${ }^{7)}$ and nanoscale electrometers for quantum information processing. ${ }^{8}$

On the other hand, nc-Si dots have been considered as a potential material for optoelectronics application since the time when room temperature photoluminescence (PL) from porous Si was observed by Canham. ${ }^{9)}$ Subsequent electroluminescence (EL) studies have achieved external quantum efficiency of $1 \%$ from porous $\mathrm{Si}^{10}{ }^{10}$ while various $\mathrm{Si}$-based light emitting devices (LEDs) made by erbium doped silicon, ${ }^{11-13)} \mathrm{Si}$ nanocrystals grown by low-pressure chemical vapor deposition (LPCVD), ${ }^{14-16)} \mathrm{Si}$ nanocrystals embedded in a $\mathrm{SiO}_{2}$ matrix, ${ }^{4,17-20)}$ field-effect electroluminescence using silicon nanocrystals, ${ }^{21)}$ and optoelectronic devices ${ }^{22)}$ have been developed. The operation of LEDs using these silicon nanocrystals also has great potential in realizing optoelectronic integrated circuits due to their process compatibility to complementary metal-oxide-semiconductor (CMOS) circuits.

We also observed PL from the surface oxidized spherical nc-Si dots. With decreasing nc-Si size, the PL peak shifted to the high energy side due to the quantum size effect. Furthermore, the PL intensity increases because of enhanced contribution from quasi-direct radiative recombination. ${ }^{23)}$ In this paper, we report EL from LEDs based on spherical nc-Si dots.

\section{Experimental Procedure}

We prepared spherically-shaped nc-Si dots with size $9 \pm 2 \mathrm{~nm}$ onto p-type $\mathrm{Si}(100)$ substrates at room temperature by applying VHF (144 MHz) plasma decomposition of $\mathrm{SiH}_{4}$ gas pulse in Ar plasma. ${ }^{3)}$ Flow rates of $\mathrm{SiH}_{4}$ and Ar were set at 1.6 and $90 \mathrm{sccm}$, respectively, with a chamber pressure of 0.03 Torr and plasma power of $1.5 \mathrm{~W}$. Si dots layers with thickness of $100 \mathrm{~nm}$ were grown. Then, the nc-Si film was thermally oxidized at $800^{\circ} \mathrm{C}$ for $8 \mathrm{~h}$ in order to reduce the size of nc-Si and enhance the luminescence intensity. ${ }^{23)}$ On top of the surface oxidized nc-Si dots layer, we prepared an n-type polycrystalline $\mathrm{Si}$ (poly-Si) layer using two different methods as described in Table I.

One set of samples (sample A) was loaded in a quartz chamber for LPCVD. Afterwards, we deposited a phosphorous doped amorphous $\mathrm{Si}(\mathrm{a}-\mathrm{Si})$ on the nc-Si layer using LPCVD and kept the temperature at $480{ }^{\circ} \mathrm{C}$ for $20 \mathrm{~min}$ under $\mathrm{Si}_{2} \mathrm{H}_{6}$ at $0.63 \mathrm{sccm}$ and $\mathrm{PH}_{3} / \mathrm{Ar}\left(\mathrm{PH}_{3}: 1 \%\right.$, Ar: $\left.99 \%\right)$ at $13.3 \mathrm{sccm}$, and with chamber pressure of 1.1 Torr. Annealing was then performed at $800^{\circ} \mathrm{C}$ for 20 s to ensure that poly $\mathrm{Si}$ was prepared using rapid thermal annealing (RTA).

The n-type poly-Si for the other set (sample B) was prepared using the following method. We deposited undoped a-Si on the nc-Si layer using LPCVD and kept the temperature at $460{ }^{\circ} \mathrm{C}$ for 9 min under $\mathrm{Si}_{2} \mathrm{H}_{6}$, which was diluted with $\mathrm{H}_{2}$ gas. The flow rate was $0.6 \mathrm{sccm}$ and the chamber pressure at 0.5 Torr. This process was followed by annealing at $1100{ }^{\circ} \mathrm{C}$ for $1 \mathrm{~h}$. The samples were then transferred to a phosphorous diffusion furnace and were kept at $950{ }^{\circ} \mathrm{C}$ for $42 \mathrm{~s}$ for doping. This process was again followed by thermal annealing at $1100^{\circ} \mathrm{C}$ for $1 \mathrm{~h}$ to activate the dopant.

Moreover light emitting diodes were then fabricated for the two sets of samples by depositing semi-transparent $\mathrm{Al}$ electrodes on top of the samples, and by forming an Al back contact. The current-voltage characteristics of the spherical nc-Si LED were measured using a Keithley 236 system. The PL was excited using $442 \mathrm{~nm}$ line of a $\mathrm{He}-\mathrm{Cd}$ laser. A 
Table I.

\begin{tabular}{|c|c|c|}
\hline & Sample A & Sample B \\
\hline $\begin{array}{c}\text { Fabrication } \\
\text { process }\end{array}$ & $\begin{array}{l}\text { nc-Si layer }(100 \mathrm{~nm}) \\
+ \text { Oxidation }\left(800^{\circ} \mathrm{C} \text {, }\right. \\
8 \mathrm{~h})+\mathrm{LPCVD} \text { of } \\
\text { P-doped a-Si + Poly- } \\
\text { crystallization ( } 800 \\
\left.{ }^{\circ} \mathrm{C}, 20 \mathrm{~s} \text { in RTA }\right)\end{array}$ & $\begin{array}{l}\text { nc-Si layer }(100 \mathrm{~nm})+ \\
\text { Oxidation }\left(800^{\circ} \mathrm{C}, 8 \mathrm{~h}\right)+ \\
\text { LPCVD of undoped a-Si } \\
+ \text { Polycrystallization } \\
\left(1100^{\circ} \mathrm{C}, 1 \mathrm{~h} \text { in Furnace }\right) \\
+\mathrm{P} \text { pre-deposition }(950 \\
\left.{ }^{\circ} \mathrm{C}, 42 \mathrm{~s}\right)+ \text { Drive-in }(1100 \\
\left.{ }^{\circ} \mathrm{C}, 1 \mathrm{~h}\right)\end{array}$ \\
\hline $\begin{array}{c}I-V \\
\text { characteristics }\end{array}$ & Ohmic & Rectifying \\
\hline Light emission & $\begin{array}{l}\text { Weak light emission } \\
\text { from the edge of the } \\
\text { electrode. }\end{array}$ & $\begin{array}{l}\text { Light emission from the } \\
\text { whole electrode area. }\end{array}$ \\
\hline
\end{tabular}

charge coupled device (CCD) array was also used for EL and PL spectral measurements at room temperature.

\section{Results and Discussion}

Figure 1(a) shows the cross-section transmission electron microscope (TEM) image of sample A before the fabrication of the top electrodes. A 15.7-nm-thick oxide layer is found between the substrate and the nc-Si layer. Because the asdeposited nc-Si dots layer has voids between individual nc$\mathrm{Si}$ dots, oxygen can diffuse through the nc-Si dots layer during the oxidation process, and as a consequence, thermal oxide was formed at the interface. In fact, the oxidation rate of this interface is almost the same as that of plain $\mathrm{Si}$ substrate. ${ }^{24)}$ Subsequent LPCVD and phosphorus diffusion processes on top of the spherical nc-Si dots layer result in quite different behavior from that of onto the usual Si layer free of voids. The site-focused TEM/energy-dispersive $\mathrm{X}$-ray (EDX) spectroscopy result shown in Fig. 1(b) indicates that phosphorous atoms diffused into the nc-Si layer and were detected even around the interface. This migration of the phosphorous atoms into the nc-Si layer was also due to the voids between spherical nc-Si dots. As a consequence, an n-type poly-Si layer is not found on top of nc-Si layer as shown in Fig. 1(a). Figure 1(c) shows the surface of the sample before electrode formation and indicates that the ncSi dots are separated by voids. Due to this non uniformity of the top layer, we could not efficiently form the electrodes even though we were able to observe weak light emission from the edge of the electrodes.

To reduce the voids between the spherical nc-Si dots, we used the reflow planarization technique. After oxidation at $800^{\circ} \mathrm{C}$ for $8 \mathrm{~h}$, nc-Si size was reduced to $5 \mathrm{~nm}$ and surface oxide thickness was increased to $4 \mathrm{~nm}$. The phosphorus present in the $\mathrm{SiO}_{2}$ layer weakens the bonds between $\mathrm{Si}$ and $\mathrm{O}$ atoms, thus reducing the melting point of the oxide. ${ }^{25)} \mathrm{In}$ sample $\mathrm{B}$, annealing at $1100^{\circ} \mathrm{C}$ for $1 \mathrm{~h}$ before P-doping establishes the formation of polycrystalline layer on top of the spherical nc-Si dots layer. Subsequent phosphorous predeposition and drive-in annealing at $1100^{\circ} \mathrm{C}$ for $1 \mathrm{~h}$ allow the P-doping in the top poly-Si layer and planarization of the nc-Si layer caused by diffused $\mathrm{P}$ atoms in the surface oxidized nc-Si layer. Figure 2(a) shows the cross-section TEM image of sample B before the fabrication of the top electrodes. The top poly-Si layer is clearly observed. A 17.2$\mathrm{nm}$-thick interfacial oxide layer is also found between the

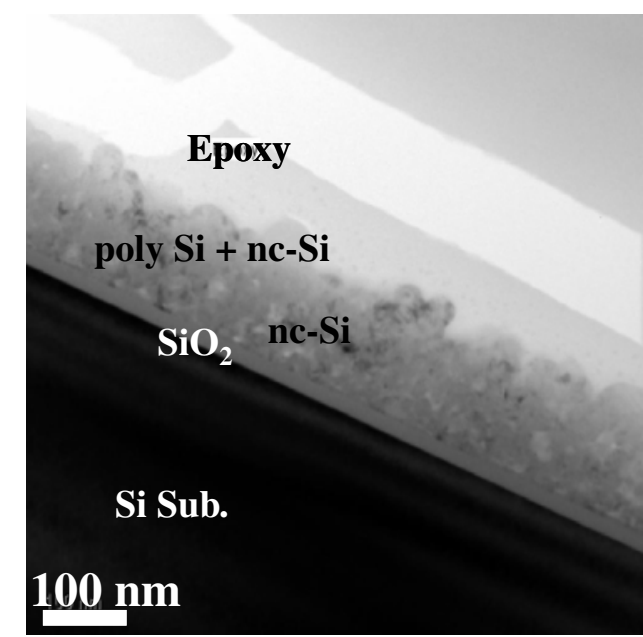

(a)

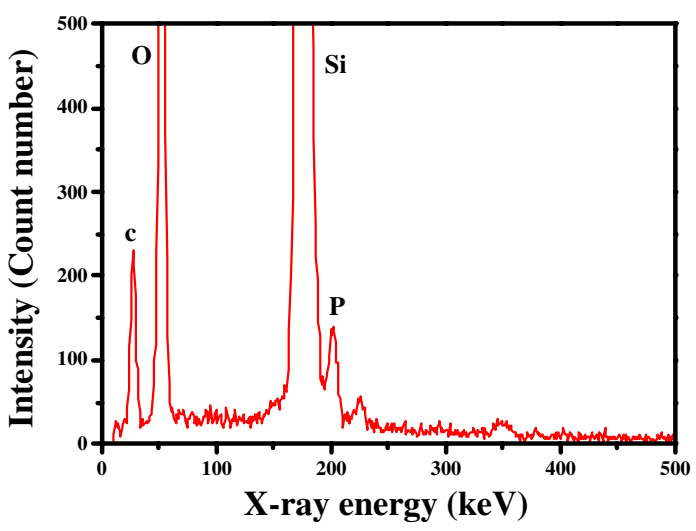

(b)

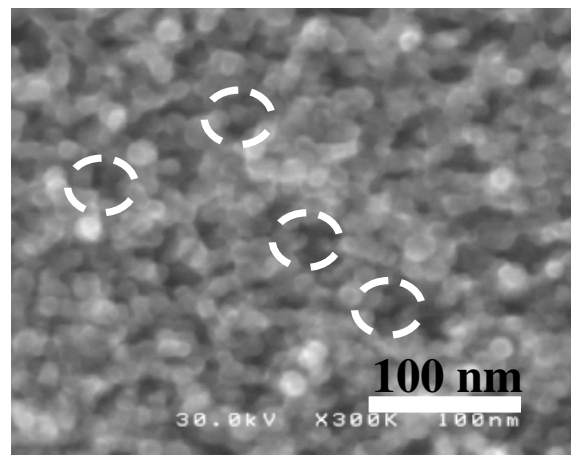

(c)

Fig. 1. (Color online) Sample A. (a) Cross-section TEM image. (b) EDX spectrum in the nc-Si layer. (c) Surface SEM image.

substrate and the nc-Si layer. Figure 2(b) shows the EDX results for sample B. In this case, the presence of phosphorus in the nc-Si layer was also detected, but in much smaller quantity than in the case of sample A. Figure 2(c) shows the surface of the sample before electrode formation. We can see that the voids separating the dots were successfully reduced compared to sample A. After deposition of the electrodes, we could observe a strong light emission from the sample B, whereas the light emission was weak in the case of sample A. Reducing the voids indeed enabled us to apply a uniform electric field in the nc-Si layer, resulting in an improvement in electron injection and light emission. 


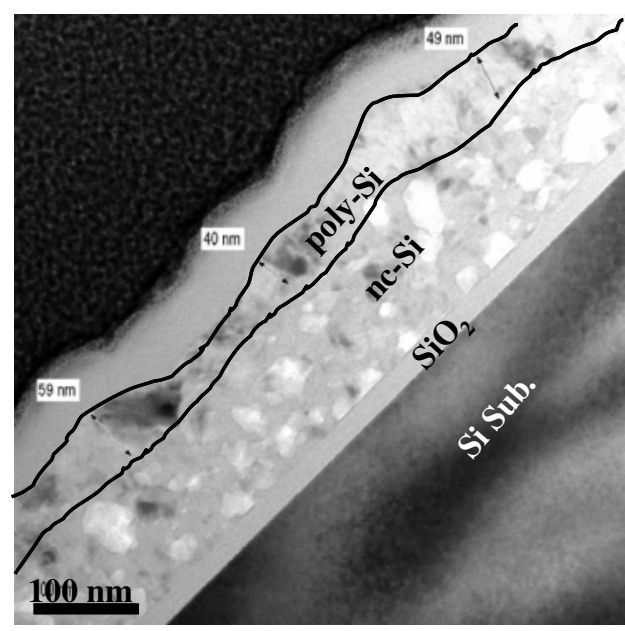

(a)

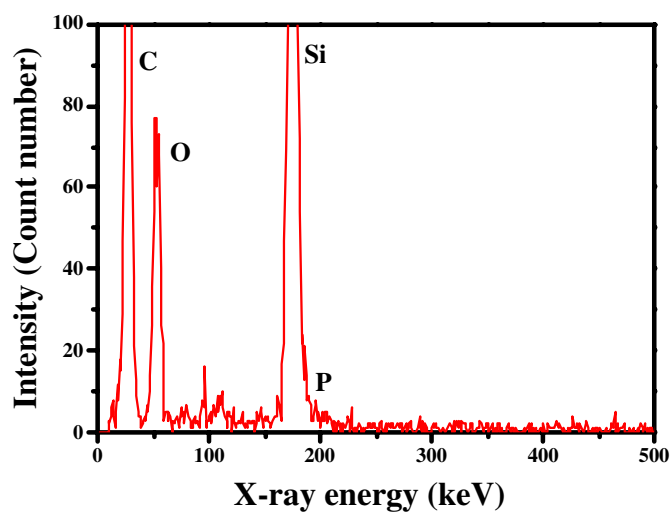

(b)

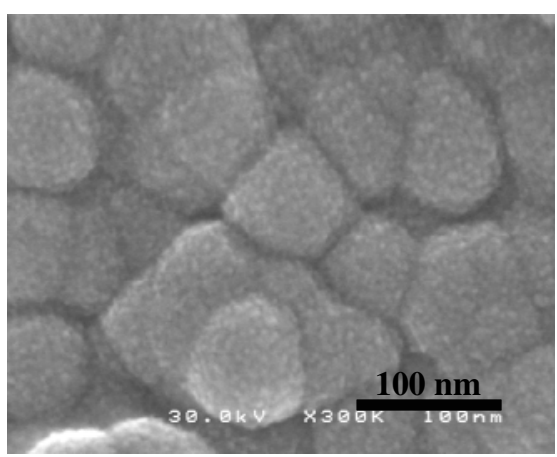

(c)

Fig. 2. (Color online) Sample B. (a) Cross-section TEM image. (b) EDX spectrum in the nc-Si layer. (c) Surface SEM image.

Figure 3(a) shows the EL from sample B. EL was visible with the naked eye in a dark room under forward bias for a voltage above $12 \mathrm{~V}$. This indicates an efficient carrier injection into silicon nanocrystals. The blue region in Fig. 3(a) also shows the Al electrode. Measured EL spectra for various bias voltages are shown in Fig. 3(b). The intensity of the EL spectra increases with the bias voltage. It should be noted that very high voltage compared to the emission energy was needed to observe EL. This is due to the existence of the interface oxide layer, which should be removed to obtain higher injection efficiency.

Next, we discuss the origin of the luminescence from ncSi samples based on a comparison between the PL and EL spectra of sample B. In our previous study, the PL spectrum

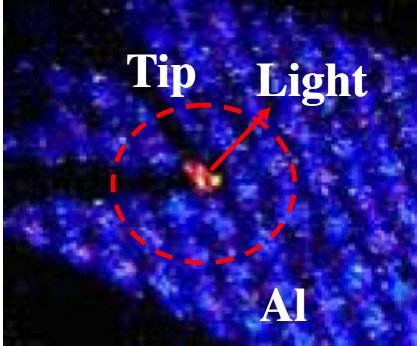

(a)

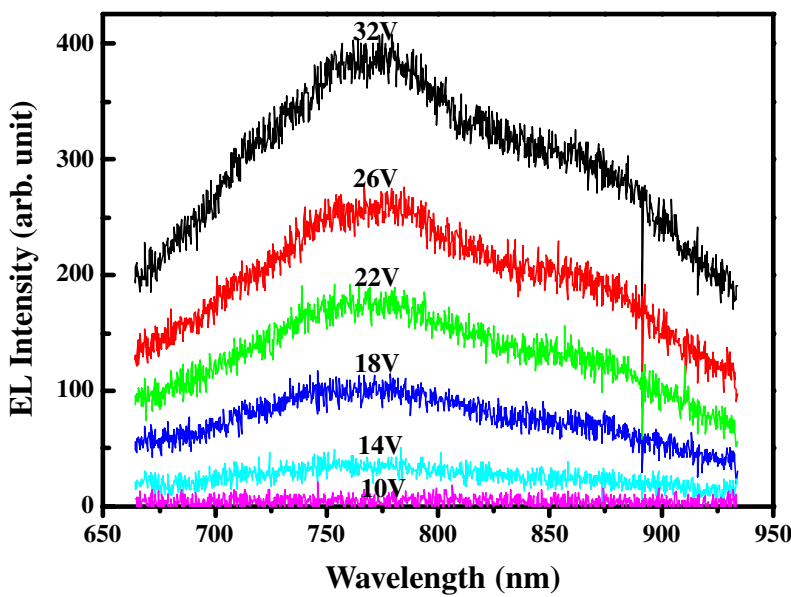

(b)

Fig. 3. (Color online) (a) EL emission from sample B. (b) EL spectra for various bias voltages.

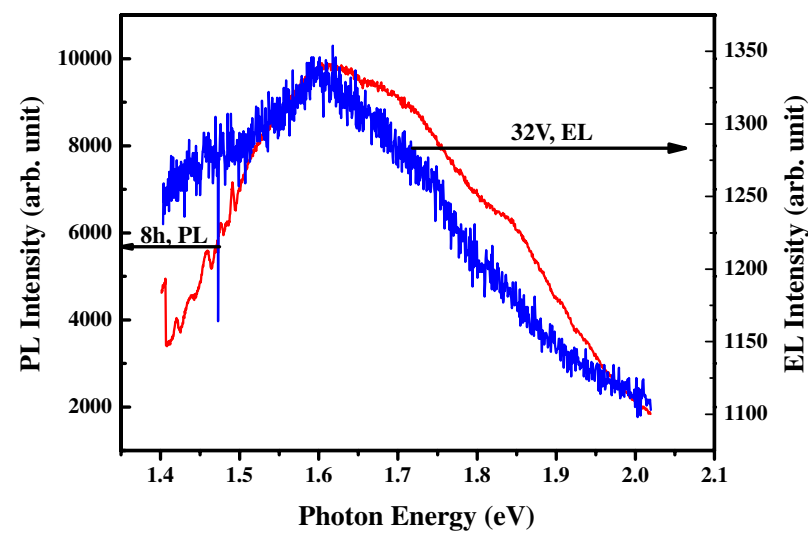

Fig. 4. (Color online) Comparison of PL and EL spectra from sample B. EL was measured with the bias voltage of $32 \mathrm{~V}$.

from surface oxidized nc-Si was de-convoluted into three peaks. ${ }^{23)}$ The dominant peak located $1.4-1.7 \mathrm{eV}$, according to the size of nc-Si. With decreasing the nc-Si size, the peak shifts to high-energy side and peak intensity increases. This peak is attributed to the radiative transition in nc-Si. A weak peak at $1.4 \mathrm{eV}$ is due to defects at the interface to between nc-Si and oxide. The peak located higher than $2.2 \mathrm{eV}$ is ascribed to defects in oxide. The PL and EL spectra of sample B are plotted simultaneously in Fig. 4. This EL measurement was done with a bias voltage of $32 \mathrm{~V}$. The EL peak position coincides with the PL main peak which is due to recombination center in nc-Si. It is notable that a shoulder is observed at $1.4 \mathrm{eV}$ due presumably to the defect at the interface between nc-Si and oxide. 


\section{Conclusions}

Electroluminescence from spherically-shaped silicon nanocrystals prepared by VHF plasma decomposition process was successfully demonstrated. The voids separating the dots were efficiently reduced by an adequate annealing process using phosphorous reflow. This process enabled us to apply a uniform electric field in the nc-Si layer, resulting in an improvement in electron injection and light emission. We also conclude that EL emission is due to electron-hole recombination center in the silicon nanocrystals because of its coincidence with the PL main peak.

\section{Acknowledgement}

The authors would like to thank Professor N. Koshida for his valuable discussions. This work was partly supported by a Grant-in-Aid for Scientific Research (19206035) from the Japan Society for the Promotion of Science.

1) A. Itoh, T. Ifuku, M. Otobe, and S. Oda: Mater. Res. Soc. Symp. Proc. 452 (1997) 749.

2) T. Ifuku, M. Otobe, A. Itoh, and S. Oda: Jpn. J. Appl. Phys. 36 (1997) 4031 .

3) K. Nishiguchi, S. Hara, T. Amano, S. Hatatani, and S. Oda: Mater. Res. Soc. Symp. Proc. 571 (2000) 43.

4) A. Irrera, D. Pacifici, M. Miritello, G. Franzo, and F. Priolo: Appl. Phys. Lett. 81 (2002) 1866.

5) J. Ohmachi, R. Nakamura, K. Nishiguchi, and S. Oda: Mater. Res. Soc. Symp. Proc. 638 (2001) F5.3.1.

6) A. Dutta, Y. Hayafune, and S. Oda: Jpn. J. Appl. Phys. 39 (2000)
L855.

7) B. J. Hinds, K. Nishiguchi, A. Dutta, T. Yamanaka, S. Hatatani, and S. Oda: Jpn. J. Appl. Phys. 39 (2000) 4637.

8) Y. Kawata, M. Khalafalla, K. Usami, Y. Tsuchiya, H. Mizuta, and S. Oda: Jpn. J. Appl. Phys. 46 (2007) 4386.

9) L. T. Canham: Appl. Phys. Lett. 57 (1990) 1046.

10) B. Gelloz and N. Koshida: J. Appl. Phys. 88 (2000) 4319.

11) G. Franzo, F. Priolo, S. Coffa, A. Polman, and A. Carnera: Appl. Phys. Lett. 64 (1994) 2235.

12) J. Palm, F. Gan, B. Zheng, J. Michel, and L. C. Kimerling: Phys. Rev. B 54 (1996) 17603.

13) J. H. Shin, M.-J. Kim, S.-Y. Seo, and C. Lee: Appl. Phys. Lett. 72 (1998) 1092

14) P. Photopoulos and A. G. Nassiopoulou: Appl. Phys. Lett. 77 (2000) 1816.

15) G. Franzò, A. Irrera, E. C. Moreira, M. Miritello, F. Iacona, D. Sanfilippo, G. Di Stefano, P. G. Fallica, and F. Priolo: Appl. Phys. A 74 (2002) 1.

16) M. V. Wolkin, J. Jorne, P. M. Fauchet, G. Allan, and C. Delerue: Phys. Rev. Lett. 82 (1999) 197.

17) N. Lalic and J. Linnros: J. Lumin. 80 (1998) 263.

18) L. Pavesi, L. D. Negro, C. Mazzoleni, G. Franzo, and F. Priolo: Nature 408 (2000) 440.

19) J. Valenta, N. Lalic, and J. Linnros: Appl. Phys. Lett. 84 (2004) 1459.

20) K. S. Cho, N.-M. Park, T.-Y. Kim, K.-H. Kim, G. Y. Sung, and J. H. Shin: Appl. Phys. Lett. 86 (2005) 071909.

21) R. J. Walters, G. I. Bourianoff, and H. A. Atwater: Nature 4 (2005) 143.

22) K. D. Hirschman, L. Tsybeskov, S. P. Duttagupta, and P. M. Fauchet: Nature (London) 384 (1996) 338.

23) K. Arai, J. Omachi, K. Nishiguchi, and S. Oda: Mater. Res. Soc. Symp. Proc. 664 (2001) A.20.6.1.

24) S. M. Sze: Physics of Semiconductor Devices (Wiley, New York, 1981) 2nd ed., Chap. 2.

25) K. Nishiguchi, X. Zhao, and S. Oda: J. Appl. Phys. 92 (2002) 2748. 